\title{
Expression and localization of cyclo-oxygenase isoforms in non-small cell lung cancer
}

\author{
D.N. Watkins***, J.C. Lenzo*, A. Segal ${ }^{+}$, M.J. Garlepp**, P.J. Thompson*
}

\begin{abstract}
Expression and localization of cyclo-oxygenase isoforms in non-small cell lung cancer. D.N. Watkins, J.C. Lenzo, A. Segal, M.J. Garlepp, P.J. Thompson. (C)ERS Journals Ltd 1999.
\end{abstract}

ABSTRACT: The beneficial effects of cyclo-oxygenase (COX) inhibitors in both colon cancer and adenomatous polyps suggest a role for the prostanoid pathway in epithelial malignancy. Although variable prostanoid synthesis in non-small cell lung cancer (NSCLC) has been demonstrated in freshly obtained tissue, COX messenger ribonucleic acid (mRNA) and protein localization in such tumours had not been investigated ex vivo.

Thirty-four cases of primary NSCLC were examined for both constitutive (COX-1) and inducible COX (COX-2) by means of in situ hybridization and immunohistochemistry.

COX-1 mRNA expression was absent or below the level of detection via in situ hybridization. COX-1 immunohistochemistry demonstrated uniform faint cytoplasmic staining in tumour cells and stromal inflammatory cells. Semiquantitative analysis of COX-2 expression in NSCLC demonstrated the highest levels of both mRNA and protein in adenocarcinoma cells $(n=10, p<0.005$ compared with large cell and squamous cell carcinoma), intermediate and variable expression in large cell carcinoma $(n=11)$ and low or absent expression in squamous cell tumours $(n=13)$. Levels of $\mathrm{COX}$ 2 expression in infiltrating inflammatory cells was the same in all tumour types.

In conclusion, tumour cell cyclo-oxygenase- 2 rather than cyclo-oxygenase-1 expression may account for the variable prostanoid production seen in non-small cell lung cancer, and primary lung adenocarcinoma expresses the highest levels of cyclooxygenase-2. Assessment of cyclo-oxygenase-2 expression ex vivo should be performed in studies examining the potential therapeutic effects of cyclo-oxygenase inhibitors in non-small cell lung cancer.

Eur Respir J 1999; 14: 412-418.

\begin{abstract}
*Asthma and Allergy Research Unit, The University Dept of Medicine, and ${ }^{+}$Dept of Pathology, Pathcentre, Queen Elizabeth II Medical Centre, Hospital Ave, Nedlands, Western Australia. **Tumour Biology, Johns Hopkins Oncology Center, Baltimore, MD, USA. Dept of Pharmacy, Curtin University, Perth, Western Australia, Australia.
\end{abstract}

Correspondence: P.J. Thompson

Asthma and Allergy Research Unit

University Dept of Medicine

Queen Elizabeth II Medical Centre

Nedlands, 6009

Western Australia

Australia

Fax: 61893462816

Keywords: Adenocarcinoma

cyclo-oxygenase

immunohistochemistry

in situ hybridization

non-small cell lung cancer prostaglandins

Received: November 181998

Accepted after revision March 301999

This research was supported by the National Health and Medical Research Council.
Non-small cell lung cancer (NSCLC) is a common and frequently lethal malignancy with an overall 5 -yr survival rate of $10-15 \%$. This cancer is often inoperable, and is frequently resistant to treatment with both chemotherapy and radiotherapy [1]. Airway epithelial cells are recognized as important sources of prostaglandins (PGs) both in vivo and in vitro [2, 3], and focal low level cyclooxygenase (COX)-2 messenger ribonucleic acid (mRNA) and protein expression in noncancerous airway epithelium from patients undergoing lung resection surgery for primary lung tumours has recently been demonstrated [4]. These data suggest that prostanoid production plays an important role in the behaviour of primary lung tumours of epithelial origin.

PGs are lipid mediators derived from arachidonic acid [5]. Arachidonic acid enters the prostanoid pathway via $\mathrm{COX}$, the rate-limiting step in the conversion of arachidonic acid to $\mathrm{PGG}_{2}$ and then $\mathrm{PGH}_{2}$ [6]. $\mathrm{PGH}_{2}$ is further metabolized to specific biologically active $\mathrm{PGs}$ by a series of tissue-specific PG synthases [5]. The constitutive form of $\mathrm{COX}(\mathrm{COX}-1)$ is widely expressed and plays a homeostatic role [7]. The inducible isoform (COX-2), normally absent from cells, is upregulated by inflammatory cytokines and growth factors, predominantly through transcriptional mechanisms [6].

The majority of studies investigating the role of prostanoids in epithelial malignancy have concentrated on colon cancer, and suggest that COX-2 expression and PG production are crucial to the growth and development of these tumours [8]. Overexpression of COX-2 [9, 10] and increased PG production [11] have been demonstrated in human colon cancer, whereas COX-1 expression is present at low levels in both normal and malignant colonic tissue [9]. Experiments in human colonic cell lines suggest that inhibition of COX-2 is associated with reduced tumour growth and the induction of apoptosis [12], and studies using systemic COX inhibitors have shown regression of human colonic polyps [13] and reductions in the formation of colonic tumours in rodents [8, 14]. More recently, a critical role for COX-2 has been demonstrated in the angiogenic response to colon cancer [15].

The importance of COX-2 expression and PG production in human lung cancer is less clear. Studies in established human lung cancer cells lines [16] and freshly 
isolated lung cancer tissue $[16,17]$ suggest that NSCLC, and in particular primary lung adenocarcinoma, is associated with the increased production of PGE2. Moreover, the cellular origins of prostanoid production and the localization of COX isoforms has not been studied in human NSCLC. Given the varied prostanoid production associated with NSCLC in vivo, it was hypothesized that expression of COX-2 in NSCLC varied according to histopathological tumour type. The aim of this study was to examine the expression and localization of both COX1 and COX-2 mRNA and protein in human NSCLC specimens obtained following surgical resection, and to correlate this expression with tumour phenotype.

\section{Materials and methods}

\section{Source of materials}

Unless otherwise stated, all were obtained from Sigma (Sydney, Australia).

\section{Tissue preparation}

Archival formalin-fixed, paraffin-embedded lung cancer specimens from patients undergoing lung resection selected at random $(n=34)$ were obtained from the Dept of Pathology, Queen Elizabeth II Medical Centre (Nedlands, Western Australia).

\section{In situ hybridization}

Localization of COX-1 and COX-2 mRNAs was performed by means of in situ hybridization, as previously described [18]. All specimens were treated identically. Sections were hybridized with an ${ }^{35}$ S-recombinant uridine triphosphate (rUTP)-labelled antisense ribonucleic acid (RNA) probe, or a complementary sense probe as a negative control. Probes were transcribed using a plasmid template containing a portion of the $\mathrm{COX}-1$ or $\mathrm{COX}-2$ complementary deoxyribonucleic acids, kindly supplied by T. Hla (Dept of Molecular Biology, Holland Laboratory, American Red Cross, Rockville, MD, USA). Autoradiography was performed for 21 days. Slides were then developed and counterstained with haematoxylin.

\section{Immunohistochemistry}

Immunolocalization of COX-1 and COX-2 protein was performed using a modification [19] of the method of ISEKI [20]. All specimens were treated in an identical fashion. Sections were incubated with a rabbit polyclonal antiCOX-1 or anti-COX-2 antibody (Cayman, Ann Arbor, MI, USA) at a concentration of $4 \mu \mathrm{g} \cdot \mathrm{mL}^{-1}$ in $1 \%$ bovine serum albumin. These antibodies have been shown to be monospecific for their respective target proteins in both paraffin-fixed tissues and immunoblots [20]. Control slides consisted of sections incubated with antibody preadsorbed with an equimolar concentration of the appropriate purified COX protein (Cayman), as previously described [20]. Following washing, sections were incubated with a biotinylated anti-mouse immunoglobulin G1 secondary antibody (Dako, Botany, Australia) for $30 \mathrm{~min}$, and then with streptavidin horseradish peroxidase (Dako) for 30 min. After peroxidase detection by means of treatment with diaminobenzidine in tris(hydroxymethyl)aminomethane-buffered saline ( $\mathrm{pH} 7.6$ ) for $5 \mathrm{~min}$, the sections were counterstained with haematoxylin and mounted.

\section{Analysis of in situ hybridization and immunohistochem- istry specimens}

Pathological diagnosis was determined independently by a pathologist (A. Segal) based on the morphological findings seen in sections adjacent to those used for in situ hybridization and immunohistochemistry. The pathological diagnosis was then reviewed and compared with the diagnosis made at the original examination at the time of lung resection. Semiquantitative scoring of in situ hybridization and immunohistochemical signals was performed, using the method described by DETRE et al. [19], by two investigators blinded to the pathological diagnosis (D.N. Watkins and J.C. Lenzo). This scoring system involves assessment of both the level of cellular expression and the percentage of cells within a given section which are positive for expression. The product of the percentage positive cell score (1-6) and the average signal intensity per cell (0-3) was recorded in six $40 \times$ objective fields in each section examined. The score for each specimen was then recorded as the mean of those of the six areas examined. Subsequently, qualitative review of all sections was performed on all specimens by two investigators (D.N. Watkins and A. Segal).

\section{Statistical analysis}

Semiquantitative scores of both in situ hybridization and immunohistochemical signals are expressed as mean \pm SEM. Comparisons between groups were made using one-way analysis of variance and Tukey's test for multiple comparisons. A p-value $<0.05$ was considered significant. Correlation between in situ hybridization and immunohistochemical scores was performed using linear regression analysis [21].

\section{Results}

\section{Histopathological analysis of tumour specimens}

Thirty-four cases of NSCLC were studied, comprising 10 adenocarcinomas, 11 large cell carcinomas and 13 squamous cell carcinomas. In all cases, review of the sections used for COX localization matched the pre-existing diagnosis. The pathological features of these tumours are summarized in table 1 .

Localization of cyclo-oxygenase-1 in non-small cell lung cancer specimens

Scattered low-level hybridization signals for COX-1 mRNA were seen throughout the tumours. This was 
Table 1. - Summary of tumour pathology

\begin{tabular}{lr}
\hline Adenocarcinoma & 10 \\
Well differentiated & 2 \\
Moderately differentiated & 6 \\
Poorly differentiated & 2 \\
Large cell carcinoma & 11 \\
Squamous cell carcinoma & 13 \\
Well differentiated & 2 \\
Moderately differentiated & 6 \\
Poorly differentiated & 6
\end{tabular}

equivalent to or slightly greater than the background levels of hybridization seen in the sense RNA controls. Immunohistochemistry demonstrated diffuse low-level cytoplasmic and nuclear COX-1 staining in tumour cells. Ablation of the cytoplasmic staining was seen following preadsorption of the antibody with purified COX-1 protein; however, the nuclear staining persisted in some sections, suggesting some nonspecific binding. Representative sections are shown in figure 1 .

Localization of cyclo-oxygenase-2 in non-small cell lung cancer specimens

COX-2 mRNA and protein expression was observed in eight of 10 adenocarcinoma specimens. Intense in situ hybridization signals were observed in tumour cells, in some cases over the entire tumour visible on the section; in others, the distribution of mRNA expression was heterogenous and varied within the tumour. Sense control sections did not demonstrate a specific hybridization signal. Similar results were observed by means of immunohistochemistry. Cytoplasmic immunoperoxidase signals were seen in tumour cells, and once again the distribution of staining varied from patchy staining of individual malignant cells to staining of the entire tumour. Neither the in situ hybridization signal nor the immunoperoxidase staining localized to the adjacent stromal tissue; however, variable cytoplasmic expression of COX-2 was seen in infiltrating mononuclear cells.

Tumour specimens of the large cell phenotype demonstrated variable and heterogeneous mRNA hybridization signals and immunoperoxidase staining for COX-2. In five of the 11 cases, COX-2 mRNA and protein were completely absent from tumour cells. In the positive cases, tumours growing as discrete islands of tissue contained intense focal perinuclear hybridization signals for COX-2 mRNA associated with cytoplasmic immunoperoxidase staining, which was more extensive and diffuse than the mRNA distribution in the adjacent sections. Positive tumours comprising sheets of poorly differentiated cells demonstrated patchy and focal COX-2 mRNA and protein expression, which was randomly distributed. Individual mononuclear cells infiltrating the tumour also demonstrated evidence of COX-2 expression; however, this was not seen in all tumour-infiltrating inflammatory cells, and nor was it seen in all tumours. Control sections for both in situ hybridization and immunohistochemistry were negative.

In nine of the 13 cases of squamous cell carcinoma, in situ hybridization and immunohistochemical signals were absent or faintly positive in the tumour cells. In three cases, diffuse weakly positive in situ hybridization signals and cytoplasmic immunostaining were observed within the major part of the carcinoma, whereas in one case, strong focal positivity for both COX-2 mRNA and protein were seen in carcinoma cells distant from central areas of keratinization. Variable levels of COX-2 expression were detected in infiltrating inflammatory cells in a similar fashion to that observed in both large cell carcinoma and adenocarcinoma. Once again, stromal areas demonstrated no specific hybridization signal or immunoperoxidase staining. Control sections for both in situ hybridization and immunohistochemistry were negative.

Representative sections from both in situ hybridization and immunohistochemical studies are shown in figure 1 .

Semiquantitative analysis of cyclo-oxygenase-2 expression

Expression of COX-2 mRNA and protein in both tumour cells and infiltrating inflammatory cells was analysed semiquantitatively. The results of this analysis are summarized in table 2 and figure 2 . There was a strong positive correlation $\left(\mathrm{r}^{2}=0.895 \mathrm{p}<0.0001\right)$ between the two blinded observers scores for both mRNA and protein expression. A positive correlation $\left(\mathrm{r}^{2}=0.730, \mathrm{p}<0.001\right)$ between tumour cell in situ hybridization and immunohistochemical scores was observed. Levels of COX-2 mRNA in adenocarcinoma cells were significantly increased compared with squamous cell carcinoma $(\mathrm{p}<0.05)$. Although there was a trend towards lower levels of COX2 mRNA expression in large cell tumours compared with adenocarcinoma, this difference did not reach statistical significance. COX-2 protein expression was also greatest in adenocarcinoma cells, and was significantly greater than that observed in both large cell carcinoma $(\mathrm{p}<0.001)$ and squamous cell carcinoma $(\mathrm{p}<0.001)$. Levels of COX2 expression in infiltrating inflammatory cells did not vary significantly with tumour type, and nor was there a significant correlation between COX-2 expression in tumour cells and adjacent inflammatory cells.

\section{Discussion}

This study investigated the differential expression of COX isoforms in NSCLC specimens obtained at thoracotomy. Although levels of COX-1 mRNA expression appeared to be below the level of detection by means of in situ hybridization, COX-1 immunohistochemistry suggested widespread low-level cytoplasmic protein expression in lung cancer cells, as well as in stromal and inflammatory cells. By contrast, COX-2 mRNA and protein expression was variable between tumour specimens, the most intense signals being seen in adenocarcinoma cells, with intermediate levels of expression in large cell tumours and the lowest levels in squamous cell carcinoma. These data suggest that $\mathrm{COX}-2$, but not $\mathrm{COX}-1$, is differentially regulated and expressed in NSCLC, and is most consistently expressed in primary lung adenocarcinoma. The possibility that tumour stage rather than phenotype may have influenced COX-2 expression cannot be excluded. However, this seems unlikely based on the following facts: 1) all tumours were deemed surgically resectable and 
a)

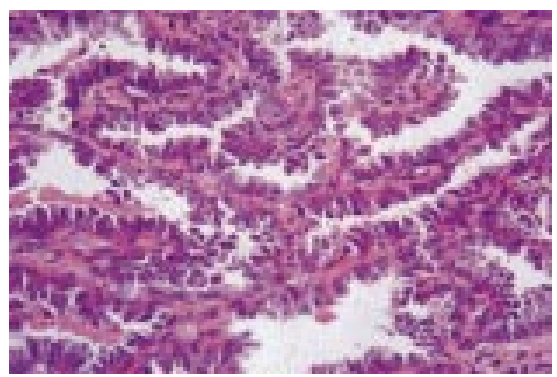

d)

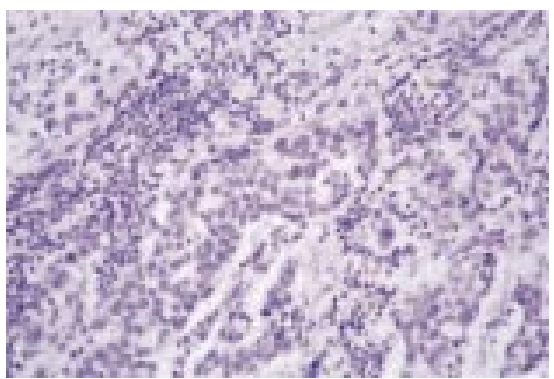

g)

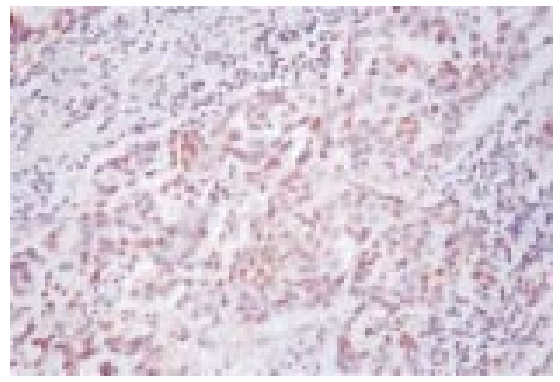

j)

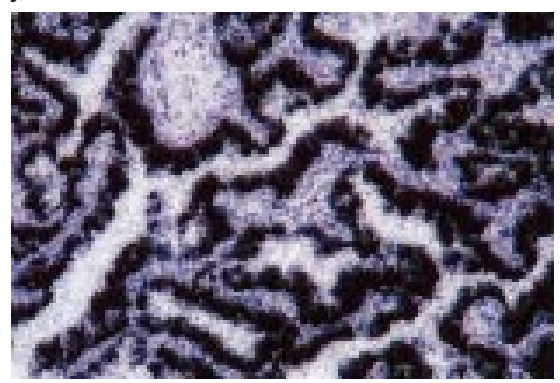

m)

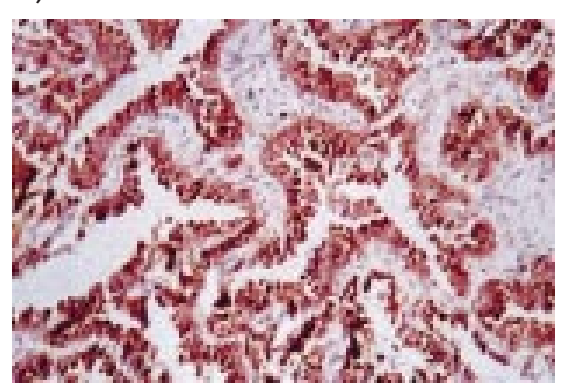

b)

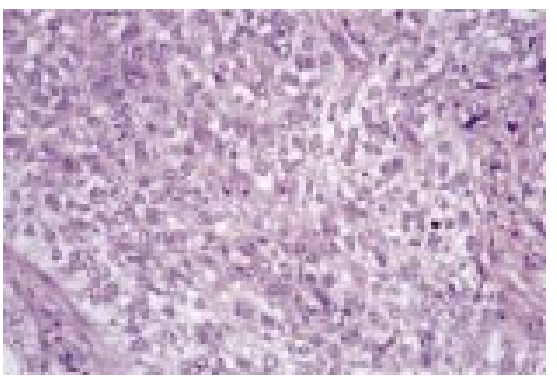

e)

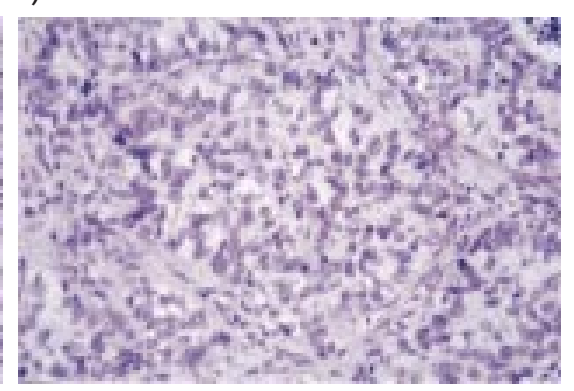

h)

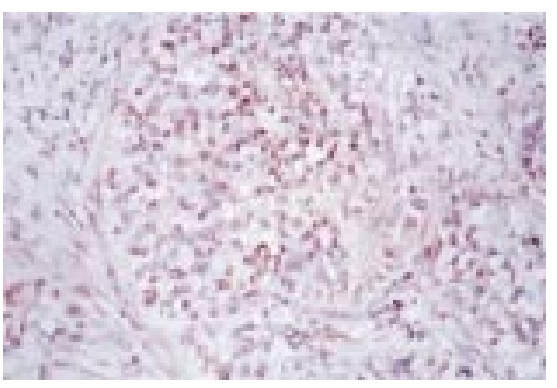

k)

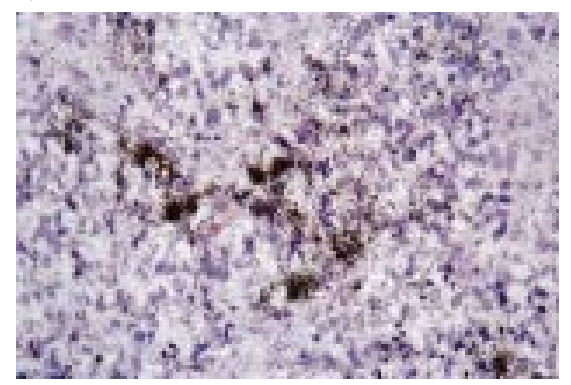

n)

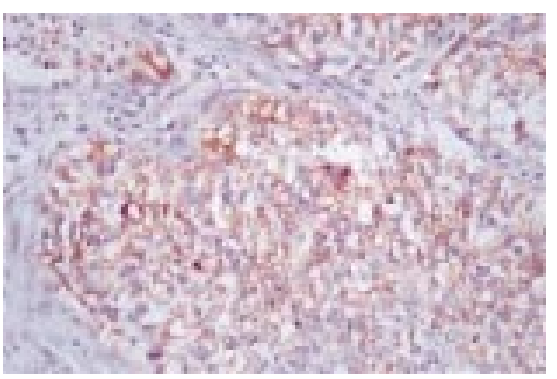

c)

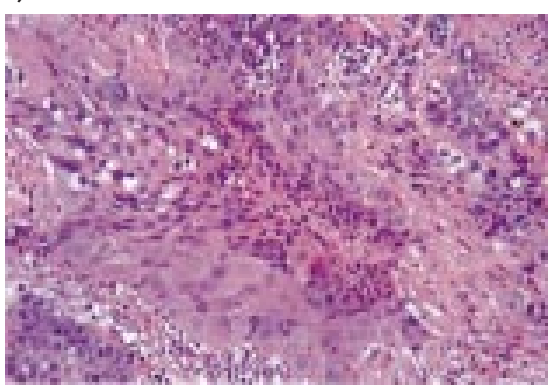

f)

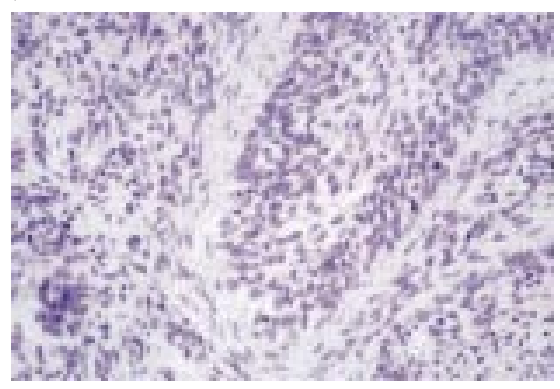

i)

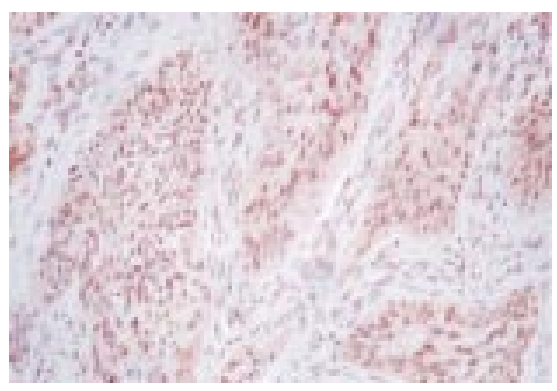

I)

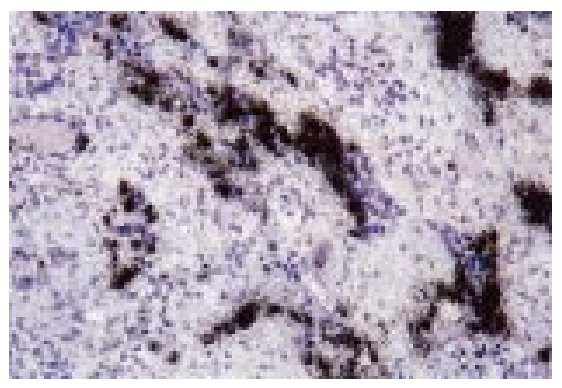

0)

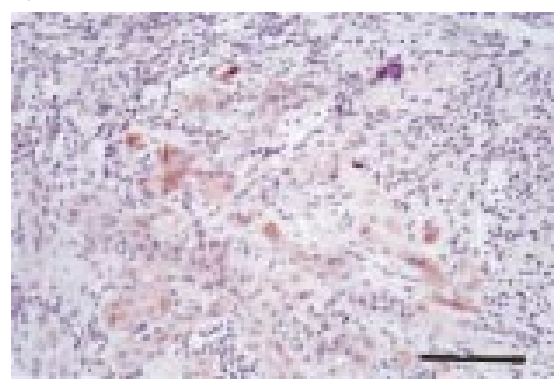

Fig. 1. - Cyclo-oxygenase (COX) localization in three primary lung carcinomas. Representative sections from each tumour type are shown: a, d, g, j, m) adenocarcinoma; b, e, h, k, n) large cell carcinoma; and c, f, i, l, o) squamous cell carcinoma. Haemotoxylin and eosin stained section; d-f, j-l) in situ hybridization study using antisense probe (d-f) COX-1; and $\mathrm{j}-1) \mathrm{COX}-2$ ); and $\mathrm{g}-\mathrm{i}, \mathrm{m}-\mathrm{o}$ ) immunohistochemistry study using COX-specific polyclonal antibody (g-i) COX-1; and $\mathrm{m}-\mathrm{o}$ ) COX-2). (Internal scale bar $=15 \mu \mathrm{m}(\mathrm{o})$ and applies to all sections of the figure.) 
Table 2. - Summary of semi-quantitative analysis of cyclo-oxygenase-2 expression in non-small cell lung cancer sections

\begin{tabular}{lcclccccc}
\hline & \multicolumn{2}{c}{$\begin{array}{c}\text { Adeno- } \\
\text { carcinoma }\end{array}$} & & \multicolumn{2}{c}{$\begin{array}{c}\text { Large cell } \\
\text { carcinoma }\end{array}$} & & \multicolumn{2}{c}{$\begin{array}{c}\text { Squamous cell } \\
\text { carcinoma }\end{array}$} \\
\cline { 2 - 3 } & ISH & IHC & & ISH & IHC & & ISH & IHC \\
\hline Mean & 9.50 & 11.20 & & 5.21 & 3.61 & & 2.22 & 0.81 \\
SD & 5.64 & 6.46 & & 4.37 & 3.22 & & 3.38 & 1.69 \\
SEM & 2.13 & 2.04 & & 1.65 & 0.97 & & 1.13 & 0.47 \\
Range & $0-18$ & $0-18$ & & $0-8$ & $0-6.75$ & & $0-8$ & $0-6$ \\
\hline
\end{tabular}

For details of scores, see Analysis of in situ hybridization and immunohistochemistry specimens section. ISH: in situ hybridisation score; IHC: immunohistochemistry score.

therefore fall within a relatively narrow range of staging, and 2) in the only comparable study, HIDA et al. [22] showed no relationship between COX-2 immunostaining and tumour stage.

Overexpression of COX-2, rather than COX-1, has been described in malignant colonic tumours $[8,9]$. These findings are supported by immunoblot analysis of COX-1 and COX-2 protein expression in malignant and normal colonic tissue [10]. Furthermore, biochemical evidence of enhanced PG production has been reported in both colon cancer [23] and primary human lung cancers ex vivo [24]. The findings in the present study suggest that, in NSCLC, expression of COX-2 by tumour cells is the mechanism responsible for the variable upregulation of prostanoid biosynthesis in primary lung cancers observed ex vivo [24], and that tumours of the adenocarcinoma phenotype are more likely to express COX-2. In addition, the expression of COX-2 in large cell carcinoma may reflect the presence of glandular differentiation not readily detectable on routine histological examination.

In a recent immunohistochemical study, HidA et al. [22] demonstrated COX-2 expression in NSCLC, but not in small cell lung cancer, and suggested, via semiquantitative analysis of immunostaining, that COX-2 expression in such tumours was upregulated compared to noncancerous airway epithelium. COX-2 expression, by means of both in situ hybridization and immunohistochemistry, has recently been investigated in nonmalignant airway epithelial cells from patients undergoing surgery for primary lung cancer [4]. Focal COX-2 mRNA expression was observed in small numbers of columnar epithelial cells, and corresponding COX-2 protein expression localized predominantly to the apical surface of the respiratory epithelial cells [4]. These findings are qualitatively different from the COX-2 expression seen in adenocarcinoma in the present study, both in the intensity of mRNA expression and the diffuse cytoplasmic localization of COX-2. However, semiquantitative comparison, given the methodology used in both studies [19], is not appropripate when comparing gene expression in solid tumours to that in lumenal structures such as airways.

Although the role of COX-2 expression in NSCLC biology has not been extensively investigated, experimental studies using both in vitro and animal models support the potential importance of COX-2 upregulation in epithelial malignancy $[14,25]$. Lewis lung carcinoma cells synthesize large amounts of $\mathrm{PGE}_{2}$ [26], and nonspecific COX inhibitors reduce their growth and metastatic potential in
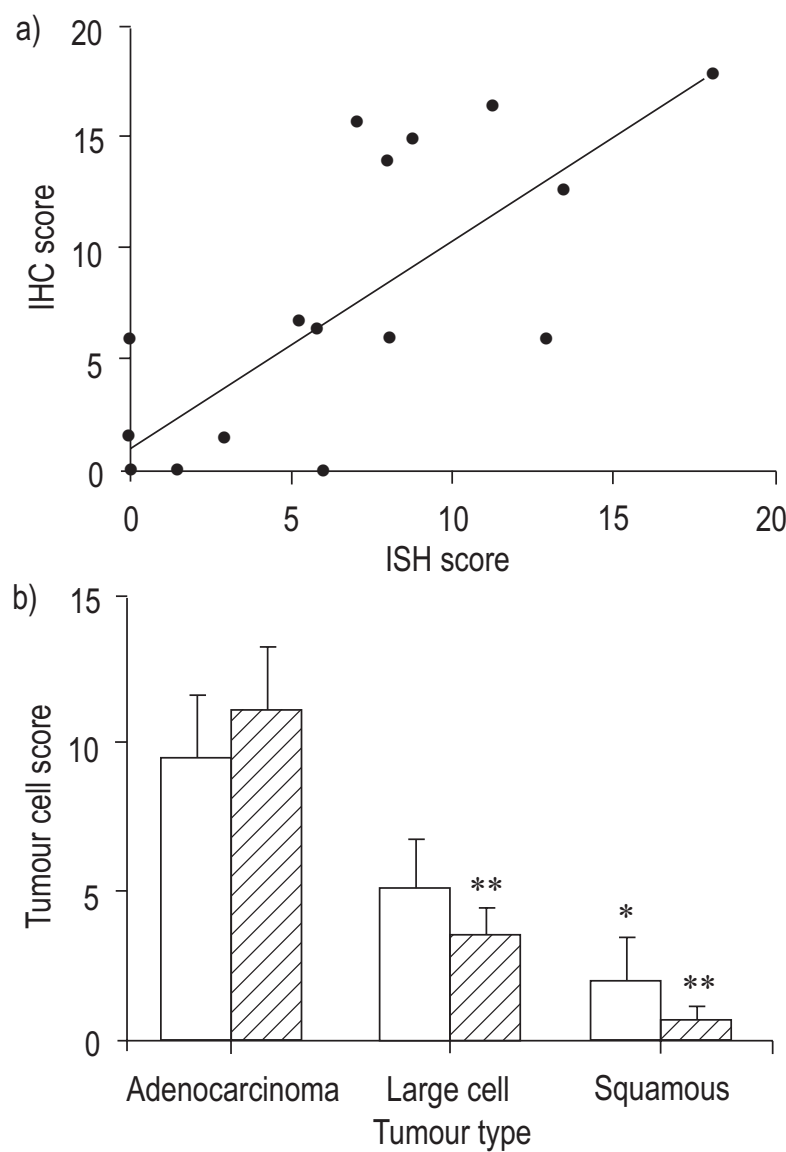

Fig. 2. - Semiquantitative analysis of cyclo-oxygenase (COX)-2 expression in non-small cell lung cancer (NSCLC): a) correlation between COX-2 in situ hybridization (ISH) and immunohistochemical (IHC) scores in NSCLC tumour cells $\left(\mathrm{r}^{2}=0.730, \mathrm{p}<0.001\right)$; and $\left.\mathrm{b}\right) \mathrm{COX}-2$ mRNA and protein expression in NSCLC tumour cells determined by semiquantitative analysis of ISH $(\square)$ and IHC $(\mathbb{Z}) . * * *$ : $<<0.05$, $\mathrm{p}<0.001$ respectively compared with adenocarcinoma. Data are presented as mean \pm SEM.

vivo [14, 27], suggesting that $\mathrm{PGE}_{2}$ production may provide a survival advantage for clones of proliferating lung cancer cells $[14,24]$. Interestingly, primary rat tracheal cells cultured in vitro undergo mucociliary differentiation in the presence of retinoic acid which is associated with $\mathrm{COX}-2$ expression and $\mathrm{PGE}_{2}$ formation [28], suggesting a specific link between the mucociliary phenotype and COX-2 induction. Although it is tempting to speculate that such a link exists in primary lung adenocarcinoma, specific studies on the expression and inhibition of COX-2 in NSCLC are required to test this hypothesis.

In colonic carcinogenesis models, early induction of COX-2 has been observed in azoxymethane-induced colonic tumours in rats [29], and in colonic epithelium exposed to a high level of dietary fat intake [30]. In human colon cancer cell lines, inhibition of the COX pathway is associated with reduced tumour growth [31] and the induction of apoptosis [12]. Moreover, specific COX-2 inhibitors reduce the growth of colonic tumour cell lines in vivo and of solid tumours in nude mice [32]. Similar studies in NSCLC systems are needed to confirm the importance of COX-2 in this context. Based on the findings in the present study, it can now be hypothesized 
that COX-2 expression may be significant in the pathogenesis and propagation of lung cancer, particularly adenocarcinoma.

In the present study, evidence consistent with upregulation of COX-2 mRNA in adenocarcinoma cells, by means of in situ hybridization, and a strong correlation between mRNA and protein expression in the NSCLC cases studied was demonstrated. These data suggest that transcriptional events may be important in COX-2 induction and expression in NSCLC. This contention is supported by extensive evidence of transcriptional regulation of $\mathrm{COX}-2$ in vitro [7, 33], and by the recent demonstration of activation of the COX-2 transcriptional apparatus in both colon and breast cancer cell lines [34]. Studies in breast cancer [34] and in several human NSCLC cell lines [35] have suggested that mutations in the ras oncogene family are directly implicated in the transcriptional activation of COX-2. Interestingly, ras mutations have been identified in $30-50 \%$ of primary lung adenocarcinomas, but are less frequent in large cell carcinoma $(21 \%)$ and squamous cell carcinoma $(5 \%)$ [36]. The present findings of marked COX-2 expression in primary lung adenocarcinoma is consistent with the hypothesis that transcriptional activation by ras may be important in the upregulation of COX2 and the production of prostanoids in NSCLC.

Studies in NSCLC have demonstrated that $\mathrm{PGE}_{2}$ is the dominant prostanoid synthesized in both cell lines [16] and fresh human lung cancer tissue [24]. Many authors have speculated that tumour-derived prostanoids, particularly $\mathrm{PGE}_{2}$, may be important in tumour invasion, the formation of metastases, and the inhibition of macrophage and $\mathrm{T}$ cell responses (reviewed in [14]). More recently, tumour COX-2 expression and prostanoid production have been directly implicated in colonic cancer angiogenesis [15]. Given the present findings of marked COX-2 overexpression in adenocarcinoma, and the clinically aggressive behaviour of this tumour when associated with oncogenic ras mutations [1], it seem likely that COX-2 expression is important for tumour growth, tissue invasion and metastasis. The potential mechanisms by which tumour-derived prostanoids may provide a survival advantage in NSCLC requires further investigation. In particular, studies in colonic carcinoma in vitro have shown that COX-2 inhibitors may induce apoptosis by a mechanism independent of $\mathrm{PGE}_{2}$ [32], suggesting that additional mechanisms may also exist in lung adenocarcinoma.

Recent interest in the effects of cyclo-oxygenase inhibitors on early carcinogenesis and tumour growth in colon cancer suggests that these agents may be of value in highrisk patients with adenomatous polyposis, and as an adjunctive therapy in established colon cancer (reviewed in [8]). In addition, emerging evidence linking the expression of cyclo-oxygenase- 2 with early events in colonic carcinogenesis as well as the promotion of tumour growth and metastasis suggests that cyclo-oxygenase- 2 specific inhibitors may be of value in this regard [8]. If in vitro studies of non-small cell lung cancer suggest that cyclooxygenase- 2 inhibition is associated with growth inhibition, reduction in metastatic potential and the induction of apoptosis, clinical trials of cyclo-oxygenase- 2 inhibitors in non-small cell lung cancer would seem warranted. Given that all patients in the present study were deemed surgically resectable, it is possible that a selection bias towards less aggressive tumours may have occurred. Despite this, the findings in this study suggest that adenocarcinoma and some large cell malignancies are the tumours most likely to respond to cyclo-oxygenase-2 inhibition. Given the variable expression of cyclo-oxygenase2 observed within each non-small cell lung cancer phenotype, the authors propose that immunohistochemical analysis of tumour cyclo-oxygenase- 2 expression be a prerequisite for any clinical trial of cyclo-oxygenase inhibitors in this form of malignancy.

Acknowledgements. The authors would like to thank the cardiothoracic surgeons and pathologists of Sir Charles Gairdner Hospital for their assistance.

\section{References}

1. Mountain CF. New prognostic factors in lung cancer. Chest 1995; 108: 246-254.

2. Holtzman MJ. Arachidonic acid metabolism in airway epithelial cells. Ann Rev Physiol 1992; 54: 303-329.

3. Watkins DN, Garlepp MJ, Thompson PJ. Regulation of the inducible cyclooxygenase pathway in cultured human airway epithelial cells by nitric oxide. $\mathrm{Br} J$ Pharmacol 1997; 12: 1482-1488.

4. Watkins DN, Peroni DJ, Lenzo JC, Knight DA, Garlepp MJ, Thompson PJ. Expression and localisation of the inducible isoform of cyclooxygenase (COX-2) in human airways and cultured human airway epithelial cells. Eur Respir J 1999; in press.

5. Sigal E. The molecular biology of mammalian arachidonic acid metabolism. Am J Physiol 1991; 260: L13-L28.

6. DeWitt D, Smith WL. Yes, but do they still get headaches? Cell 1995; 83: 345-348.

7. Herschmann HR. Regulation of prostaglandin synthase 1 and prostaglandin synthase 2. Cancer Metastasis Rev 1994; 241: 241-256.

8. Gustafson-Svard C, Lilija I, Hallbook O, Sjodahl R. Cyclo-oxygenase and colon cancer: clues to the aspirin effect? Ann Med 1997; 29: 247-252.

9. Sano H, Kawahito Y, Wilder RL. Expression of cyclooxygenase 1 and 2 in human colorectal cancer. Cancer Res 1995; 55: 3785-3789.

10. Kargman SL, O'Neill GP, Vickers PJ, Evans JF, Mancini JA, Jothy S. Expression of prostaglandin G/H synthase 1 and 2 protein in human colon cancer. Cancer Res 1995; 55: 2556-2559.

11. Rigas B, Goldman IS, Levine L. Altered eicosanoids levels in human colon cancer. J Lab Clin Med 1993; 122: 518-523.

12. Piazza GA, Rahm AK, Finn TS, et al. Apoptosis primarily accounts for the growth inhibitory properties of sulindac metabolites and involves a mechanism that is independent of cyclooxygenase inhibition, cell cycle arrest and p53 induction. Cancer Res 1997; 57: 2452-2459.

13. Spagnesi M, Tonelli F, Dolara P. Rectal proliferation and polyp recurrence in patients with familial adenomatous polyposis after sulindac treatment. Gastroenterology 1994; 106: 362-366.

14. Ara G, Teicher BA. cyclooxygenase and lipoxygenase inhibitors in cancer therapy. Prostaglandins Leukot Essent Fatty Acids 1996; 54: 3-16.

15. Tsujii M, Kawano S, Tsuji S, Sawaoka S, Hori M, Du Bois RN. cyclooxygenase regulates angiogenesis induced by colon cancer cells. Cell 1998; 93: 705-716. 
16. Hubbard WC, Alley MC, McLemore TL, Boyd MR. Profiles of prostaglandin biosynthesis in sixteen established cell lines derived from human lung, colon, prostate and ovarian tumours. Cancer Res 1988; 48: $4770-4775$.

17. Hubbard WC, Alley MC, Gray GN, Green KC, McLemore TL, Boyd MR. Evidence for prostanoid biosynthesis as a biochemical feature of certain subclasses of non-small cell carcinomas of the lung as determined in established cell lines derived from human lung tumours. Cancer Res 1989; 49: 826-832.

18. Watkins DN, Peroni DJ, Basclain KA, Garlepp MJ, Thompson PJ. Expression and activity of nitric oxide syntheses in human airway epithelium. Am J Respir Cell Mol Biol 1997; 16: 629-639.

19. Detre S, Saccani Jotti G, Dowsett M. A quickscore method for immunohistochemical semiquantitation: validation for oestrogen receptor in breast carcinomas. J Clin Pathol 1995; 48: 876-878.

20. Iseki S. Immunocytochemical localisation of cyclooxygenase 1 and cyclooxygenase 2 in the rat stomach. Histochem $J$ 1995; 27: 323-328.

21. Page RM, Cole GE, Timmreck TC. Basic epidemiological methods and biostatistics: a practical guidebook. (First ed.) Boston, Jones and Bartlett, 1995.

22. Hida $\mathrm{T}$, Yatabe $\mathrm{Y}$, Achiwa $\mathrm{H}$, et al. Increased expression of cyclooxygenase 2 occurs frequently in human lung cancers, specifically in adenocarcinomas. Cancer Res 1998; 58: 3761-3764.

23. Vergote IB, Laekman GM, Keersmaekers GH. Prostaglandins $\mathrm{F}_{2 \alpha}$ in benign and malignant breast tumours. $\mathrm{Br} \mathrm{J}$ Cancer 1985; 51: 827-836.

24. McLemore TL, Hubbard WC, Litterst CL, et al. Profiles of prostaglandin biosynthesis in normal lung and tumour tissue from lung cancer patients. Cancer Res 1988; 48: 3140-3147.

25. Lupulescu A. Prostaglandins, their inhibitors and cancer. Prostaglandins Leukot Essent Fatty Acids 1996; 54: 8394.

26. Young MRJ, Duffie GP, Lozano Y, Young ME, Wright MA. Association of a functional prostaglandin $\mathrm{E}_{2}$ protein kinase A coupling with responsiveness of metastatic lewis lung carcinoma variants to prostaglandin $\mathrm{E}_{2}$ and to prostaglandin $\mathrm{E}_{2}$ producing nonmetastatic lewis lung carcinoma variants. Cancer Res 1990; 50: 2973-2978.

27. Chiabrando C, Broggini M, Castagnoli MN. Prostaglandin and thromboxane synthesis by Lewis lung carcinoma during growth. Cancer Res 1985; 45: 3605-3608.

28. Hill EM, Bader T, Nettesheim P, Eling TE. Retinoid induced differentiation regulated prostaglandin $\mathrm{H}$ synthase and cPLA $_{2}$ expression in tracheal epithelium. $A m J$ Physiol 1996; 270: L854-862.

29. DuBois RN, Radhika A, Reddy BS, Entingh AJ. Increased cyclooxygenase 2 levels in carcinogen induced rat colonic tumours. Gastroenterology 1996; 110: 12591262.

30. Singh J, Hamid R, Reddy SS. Dietary fat and colon cancer: modulation of cyclooxygenase 2 by types and amount of dietary fat during the post-initiation stage of colon carcinogenesis. Cancer Res 1997; 57: 3465-3470.

31. Hanif R, Pittas A, Feng Y, et al. Effects of nonsteroidal anti-inflammatory drugs on proliferation and on induction of apoptosis in colon cancer cells by a prostaglandin independent pathway. Biochem Pharmacol 1996; 52: 237-245.

32. Sheng H, Shao J, Kirkland SC, et al. Inhibition of human colon cancer cell growth by selective inhibition of cyclooxygenase 2. J Clin Invest 1997; 99: 2254-2259.

33. Goppelt-Stuebe M. Regulation of prostaglandin endoperoxide synthase (cyclooxygenase) isozyme expression. Prostaglandins Leukot Essent Fatty Acids 1995; 52: 213 222.

34. Subbaramaiah K, Telang N, Ramonetti JT, et al. Transcription of cyclooxygenase- 2 is enhanced in transformed mammary epithelial cells. Cancer Res 1996; 56 : 4424-4429.

35. Heasley LE, Thaler S, Nicks M, Price B, Skorecki K, Nemenoff RA. Induction of cytosolic phopsholipase $\mathrm{A}_{2}$ by oncogenic ras in human non small cell lung cancer. $J$ Biol Chem 1997; 272: 14501-14504.

36. Carbone DP, Minna JD. The molecular genetics of lung cancer. Adv Internal Med 1997; 37: 153-171. 